\title{
PROMOVENDO A CONSCIENTIZAÇÃO AMBIENTAL: RESULTADOS DE UMA PESQUISA REALIZADA COM ALUNOS DO ENSINO MÉDIO SOBRE POLÍMEROS, PLÁSTICOS E PROCESSOS DE RECICLAGEM
}

\author{
Maiza da Silva Ozório ${ }^{1}$ \\ Moacir Pereira de Souza Filho ${ }^{2}$ \\ Neri Alves ${ }^{3}$ \\ Aldo Eloizo Job ${ }^{4}$
}

Resumo: Este artigo apresenta os resultados de uma pesquisa realizada com alunos do ensino médio referente aos temas: polímeros, plásticos e reciclagem. A intervenção buscou fornecer elementos para conscientização e reflexão sobre problemas ambientais, além de despertar nos alunos um pensamento crítico. Dentre as etapas da pesquisa estão o levantamento dos conhecimentos prévios, obtidos por meio de um questionário, além de ações de informação e conscientização implementadas através de um seminário ministrado sobre 0 tema. A inferência dos resultados apresenta-se como uma alternativa de ensino interessante para educação escolar, uma vez as propostas de ações sugeridas pelos alunos, revelam uma dimensão social que extrapola os "muros" escolares.

Palavras-chave: Polímeros; Plásticos; Reciclagem; Educação Ambiental.

\footnotetext{
${ }^{1}$ Universidade Estadual Paulista (FCT/Unesp/Pres.Prudente). Email: ozoriounesp@gmail.com

${ }^{2}$ Universidade Estadual Paulista (FCT/Unesp/Pres.Prudente). Email: moacir@fct.unesp.br

${ }^{3}$ Universidade Estadual Paulista (FCT/Unesp/Pres.Prudente). Email: $\underline{\text { neri@fct.unesp.br }}$

${ }^{4}$ Universidade Estadual Paulista (FCT/Unesp/Pres.Prudente). Email: job@fct.unesp.br
} 


\section{Características e aplicações dos Polímeros e Plásticos}

Os polímeros são moléculas muito grandes formadas por unidades moleculares que se repetem, denominadas monômeros. Esses materiais, devido as suas características físicas e químicas, possuem propriedades interessantes tais como, alta flexibilidade, alta resistência ao impacto, baixas temperaturas de processamento, baixa condutividade elétrica e térmica, porosidade, reciclabilidade, dentre outras (MANO et. al., 2000). Tais propriedades permitem que os polímeros sejam utilizados em diversas aplicações, como na indústria têxtil, construção civil, indústria dos transportes, da qual se destaca a indústria automobilística, indústria farmacêutica, produção de embalagens, indústria de eletrodomésticos, etc. (Figura 1).
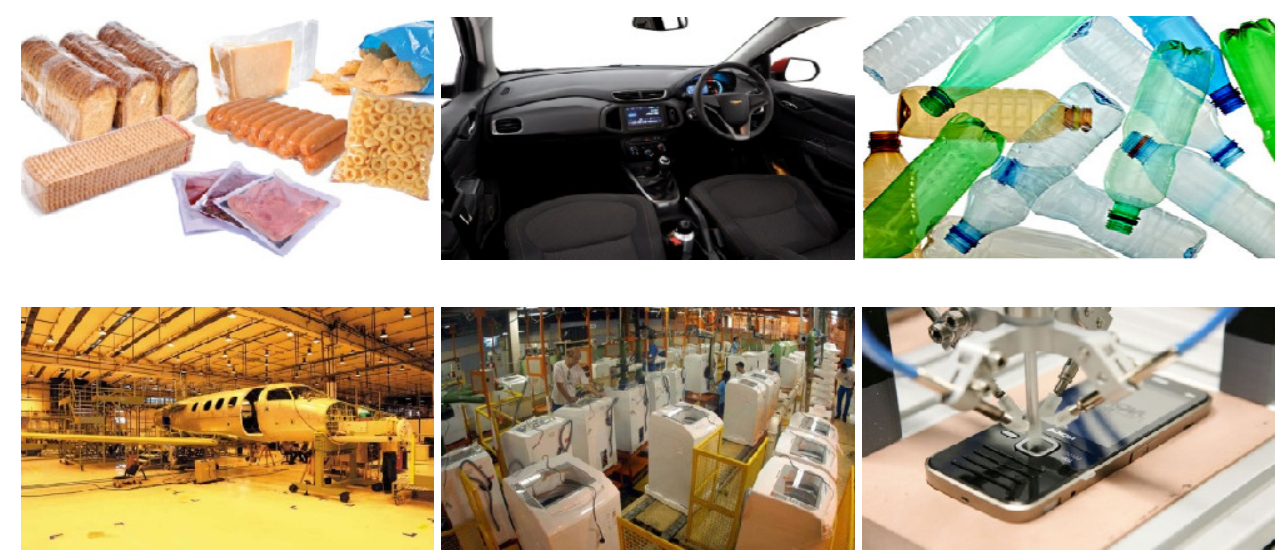

Figura 1: Exemplos das diversas aplicações dos polímeros, desde a armazenação e conservação de alimentos, até tecnologias mais avançadas. Fonte: Silva (2013).

Dentre a diversidade de materiais poliméricos podemos destacar os plásticos. O termo "plástico" aplica-se ao material macromolecular constituído por polímeros e aditivos que lhe conferem propriedades de interesse no processamento ou nas aplicações. Por sua vez, os aditivos são substâncias químicas que se adicionam ao polímero para obter propriedades específicas ou para facilitar a sua transformação, podendo assim ser moldado ou reciclado (DE PAOLI, 2008).

Os plásticos, que tem seu nome originário do grego plastikos, significa capaz de ser moldado - são materiais sintéticos ou derivados de substância naturais, geralmente orgânicas, obtidas atualmente, em sua maioria, a partir dos derivados de petróleo (BOTELHO et. al., 2011). Segundo Canevarolo (2002) esses materiais interagem de modo intenso e diário na vida das pessoas, a sua presença é constante nos mais variados setores e com as mais diversas aplicações estando presente desde produtos simples, como também, em produtos complexos que exigem tecnologia de última geração para serem fabricados. Sendo assim, não é difícil concluir que os polímeros invadiram todos os domínios da atividade humana e devido as suas vertentes científica, 
tecnológica e comercial, esses materiais influenciam decisivamente na sociedade, continuando-se a observar uma tendência, aliás, crescente, para substituírem muitas matérias-primas tradicionais, num número cada vez maior de aplicações.

Neste contexto, com o desenvolvimento da Ciência e Tecnologia dos Polímeros, e tomando como exemplo, a necessidade de acondicionar alimentos visando prolongar sua vida útil e, consequentemente, seu tempo de validade, a demanda de embalagens e produtos descartáveis aumentou significativamente nas últimas décadas. Se por um lado estas embalagens facilitam o transporte e asseguram as condições de conservação e higiene dos produtos, por outro, provocam problemas com a quantidade de resíduos produzidos, uma vez que estes, na sua maioria, não são biodegradáveis e são de difícil decomposição pelo processo natural. Desse modo, o gerenciamento correto dos resíduos poliméricos representa um tema bastante relevante na atualidade, pois além de exercer uma ação direta sobre meio ambiente, está intrinsecamente relacionado à nossa sociedade, atingindo a nossa economia e até mesmo nossos padrões de comportamento humano.

Para Almeida et. al. (2013) com a crescente opção por alimentos industrializados, pode-se verificar uma relação direta entre a alimentação e a geração de resíduos. O lixo gerado por esta relação é resultado do estilo ou padrão de vida da sociedade, pois, "quanto mais rica e consumista ela [a sociedade] for, mais geradora de lixo ela será".

\section{A importância da reciclagem e da Educação Ambiental}

A reciclagem surge então como uma das possíveis soluções para minimizar os malefícios causados pelo uso massivo de materiais poliméricos pela sociedade em desenvolvimento. Porém, por razões culturais, o ser humano ainda resiste em fazer da reciclagem uma prática habitual. Sendo assim, para dar início a essa longa jornada, de aprendizagem crítica e consciente, é necessário que as pessoas comecem a se familiarizar com o assunto o quanto antes, e nada melhor que o ambiente escolar para trazer à tona essa atitude ambiental emergente (Figura 2).

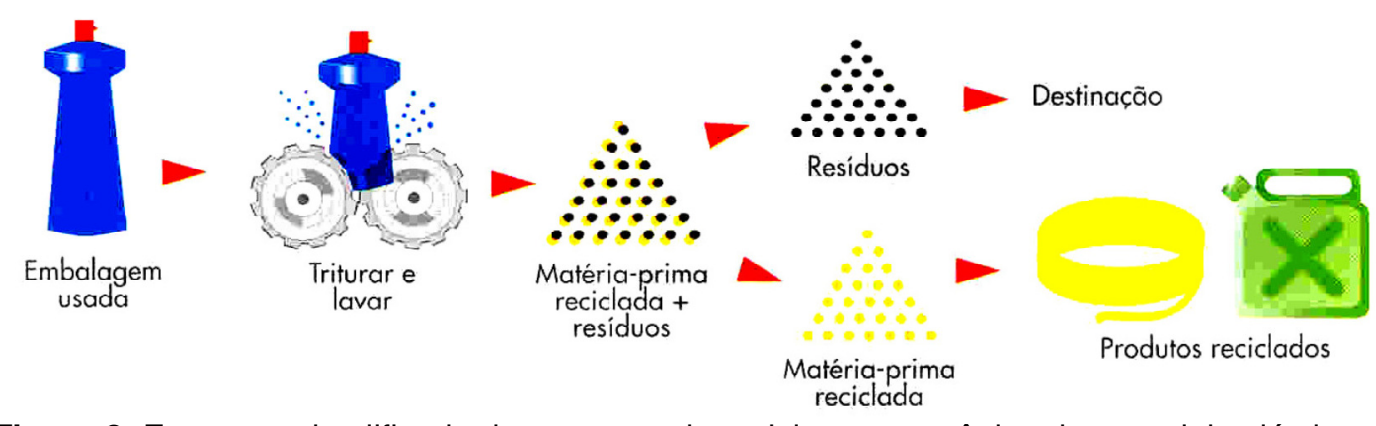

Figura 2: Esquema simplificado do processo de reciclagem mecânica de materiais plásticos. Fonte: http://www.plastivida.org.br/2009/Reciclagem Mecanica.aspx 
Nos Parâmetros Curriculares Nacionais (PCNs) está presente um discurso de que a educação deve propiciar as relações com o "cotidiano" do aluno, visto que seria possível "dar significado ao conteúdo curricular", realizando uma ligação "ao que se aprende na escola e ao que se faz, vive e observa no dia a dia" (BRASIL, 2013). Desse modo, a escola seria capaz de proporcionar, o exercício da cidadania presente na legislação e nos currículos, compondo assim diferentes discursos que circulam nos meios de comunicação, regulando e instituindo significados e modos de agir em sociedade. Além disso, esta prática promoveria a inserção do conhecimento disciplinar nos diferentes setores da sociedade, com reflexos imediatos em aspectos políticos, econômicos e sociais e com a conscientização do imprescindível papel desempenhado pela tecnologia e cultura contemporâneas (MARCONDES et. al., 2009). Mas, infelizmente, ainda existem muitas barreiras a serem vencidas, principalmente quando se trata do ensino que promova a consciência ambiental, pois, a maioria das escolas brasileiras não contempla um ensino voltado para a sociedade e seus problemas, como preconizado pelas diretrizes curriculares.

O que se vê nas escolas é uma aprendizagem mecânica baseada na racionalidade técnica, ao invés de uma aprendizagem significativa, na qual o aluno participa ativamente do processo. Não existem debates, e isso prejudica a formação de opinião por partes dos alunos, além de tornar a aprendizagem inadequada e desestimulante. Os alunos precisam descobrir e conhecer melhor a sociedade em que vivem e se engajarem nos reais problemas que se vinculam ao desenvolvimento sustentável. Segundo Mazzarino et. al. (2012, p. 54):

Os processos educativos contam ainda, quase que exclusivamente com quadro-negro, giz e salas de aula em espaços fechados, onde se dá a transmissão dos conteúdos via livros didáticos, com a verificação de aprendizagem dos alunos. Dessa forma, o currículo escolar constitui-se na possibilidade de conhecer as informações sem vivenciá-las, experimentá-las e sem inseri-las num contexto. Aprende-se conhecimentos experenciados por outras pessoas, de tal forma que, aquele que aprende está separado daquilo que é aprendido.

Além de informações e conceitos, também é importante que a escola trabalhe com atitudes e formação de valores com metodologias e procedimentos adequados. E esse é um grande desafio para a educação. Os educadores, de uma maneira geral, acreditam que, para realizar uma educação ambiental numa perspectiva mais holística e não tão conservadora, faz-se necessário que a escola, como um todo, elabore projetos pedagógicos coerentes e que operacionalizem qualquer atividade que tenha como objetivo a educação ambiental consciente. O projeto de educação ambiental é útil no sentido de esclarecer ao aluno sobre os benefícios da reciclagem dos resíduos 
e a conscientização da preservação do meio ambiente, podendo ser trabalhado em paralelo às competências e habilidades a serem desenvolvidas no ensino médio (SANTOS et. al., 2011).

No âmbito educacional, a reciclagem gera oportunidades de mobilização e participação comunitárias, desenvolvendo nos cidadãos a consciência ambiental e uma atitude de responsabilidade em relação ao lixo gerado por eles. Desse modo, o sistema educacional tem um papel fundamental em fazer com que todos entendam o atual cenário no qual estamos inseridos, particularmente no que diz respeito à reciclagem (REIS; MELO, 2013). A sua contribuição emerge como uma reflexão crítica sobre esta problemática e estimula um debate acerca da formação de cidadãos protagonistas dessa realidade difícil de ser encarada, porém, extremamente necessária.

Uma das formas de abordar a educação ambiental nas escolas é fazendo a junção entre a reciclagem e os resíduos poliméricos, na qual os alunos possam compreender a intersecção ou a relação entre esses dois temas, compreender a importância do desenvolvimento e da sustentabilidade na sociedade em que vive, vincular-se e conhecer melhor como os polímeros influenciam nos padrões de vida das pessoas e como lidar com os possíveis problemas sociais e ambientais que esses materiais podem causar. Para isso são necessários professores comprometidos em preparar ações educativas sobre reciclagem nas escolas. A ação do professor é fundamental, porque é ele quem vai proporcionar aos alunos as condições necessárias à mudança de comportamento para que se tornem cidadãos conscientes da importância das suas atitudes em relação à preservação da natureza e do consumismo consciente.

Neste sentido, o trabalho de Mattos e Peres (2010) apresenta, aos alunos de 5a . e 6”a . série, um documentário em uma linguagem simples "The story of stuff" (a história das coisas); promove uma palestra sobre as formas de reduzir, reutilizar e reciclar os plásticos, além de elaborar e distribuir "folders" explicativos, informando e sensibilizando os alunos sobre os problemas e possíveis soluções para a comunidade.

Outro exemplo, a ser citado é a pesquisa desenvolvida por Oliveira (2010), visando fomentar um ensino que lhe forneça embasamento para posicionamento crítico do aluno, com valores éticos perante a sociedade. A pesquisadora elaborou e testou uma sequência didática baseada na teoria freiriana e sob o enfoque CTS, ressaltando as questões sócio-científicas e enfocando o tema "polímeros", com a utilização de vídeos, poesias e questões norteadoras do processo, em slides. Os educandos expuseram suas ideias, revoltas e angústias sobre a situação dos plásticos na sociedade, o que possibilitou a delimitação da temática. Os resultados apontam para necessidade de instaurar correlações entre os conhecimentos científicos e conhecimentos cotidianos, uma vez que eles não se mostraram preparados 
para se posicionarem criticamente e tomar decisões perante as situações vividas pela sociedade.

O trabalho feito por Mesquita et. al. (2010) aponta, por meio de um mapa conceitual, algumas possibilidades para se trabalhar com os temas geradores "plásticos" e "polímeros" no ensino, a fim de problematizar o processo de descarte e discutir a importância de alternativas que venham minimizar a produção de lixo oriundo deste tipo de material. Como exemplo, os autores sugerem atividades tais como textos, experimentação, vídeos e jogos.

Para Almeida et. al. (2013), os projetos e ações abordam o assunto do "lixo" apenas sob a perspectiva do "pós-consumo", ou seja, o que fazer com o lixo gerado? Portanto, o trabalho propõe como objetivos específicos ressaltar a importância de hábitos alimentares saudáveis, como forma de melhorar a qualidade de vida, ao mesmo tempo que promove uma educação ambiental transformadora. $O$ trabalho se divide em etapas tais como: palestra aos pais sobre a relação entre a alimentação e a produção de lixo; cardápio formulado para cada criança, visando uma alimentação mais natural; uma nova palestra aos pais sobre a fisiologia da digestão; uma terceira palestra ministrada por uma equipe multidisciplinar (nutricionistas, dentistas, etc.); passeio em uma fazenda com um programa voltado a educação alimentar e ambiental; oficina de pintura de sacolas retornáveis; além de oficina de culinária com a participação ativa das crianças (com receitas e orientações). Como resultado do projeto os alunos passaram a consumir durante os recreios, lanches naturais, ao invés de chocolates, bolachas recheadas e salgadinhos. Consequentemente, houve impactos positivos tanto na saúde dos envolvidos, quanto, na redução de resíduos sólidos.

Estes exemplos de aplicações no contexto escolar nos fazem refletir que:

A dimensão ambiental pode se configurar como um fator desencadeador de ações éticas e humanísticas, de ações que transcendem contextos e fronteiras. Agir dessa forma exige ultrapassar as amarras estabelecidas pelo currículo disciplinar e pelos muros da escola (MAZZARINO et. al., 2012, p. 59).

Neste contexto, a proposta deste trabalho foi a de utilizar os polímeros e a reciclagem como tema motivador do processo de ensino e aprendizagem. Os principais objetivos foi proporcionar aos alunos a oportunidade de discussão sobre polímeros, sua importância na sociedade, os problemas ambientais causados por eles, despertando esses estudantes para uma atitude consciente, ativa e crítica, quanto à importância do desenvolvimento sustentável, quanto às condições básicas, necessárias para que a sua vida, a de seus familiares e de toda a comunidade na qual estão inseridos, a fim de que eles se tornem mais conscientes quanto a sustentabilidade. 
É valido ressaltar que temas como reciclagem não devem ser discutidos apenas nas escolas, pois, fazem parte de um processo e, portanto, deve ser trabalhado e desenvolvido por todos integrantes da sociedade. Essa é uma atitude eminente trazida pela preocupação com os problemas ambientais que, devido à sua relevância não podem mais ser ignorada.

\section{Metodologia do trabalho investigativo}

A motivação da pesquisa surgiu da preocupação da autora deste trabalho com a conscientização dos estudantes em relação aos problemas ambientais e da necessidade de ações que realmente se efetivassem.

O curso de licenciatura em Física da Unesp de Presidente Prudente, requer como requisito ao final da graduação, que os alunos apresentem um Trabalho de Conclusão de Curso (TCC) relacionado diretamente ao ensino. Neste sentido, a pesquisadora resolveu unir seu trabalho de pesquisa em iniciação científica (que está relacionado aos plásticos e polímeros) com a sua formação docente (aproveitando o período de estágio supervisionado para implementar ações no ambiente escolar) (OZÓRIO, 2013).

O trabalho foi realizado na Escola Estadual "Angélica de Oliveira", situada no município de Álvares Machado/SP. Essa pesquisa foi realizada em 2 (duas) turmas do 2 ㅇ e $3^{\circ}$ ano do Ensino Médio, totalizando 80 alunos participantes da amostra. O objetivo da pesquisa foi debater o tema "polímeros e reciclagem", fazendo com que os alunos relacionassem o conhecimento desenvolvido ao longo de sua vivência na escola com o cotidiano e discutissem sobre a importância da reciclagem em uma sociedade em desenvolvimento. Como materiais de apoio, foram utilizadas fontes de referências como livros, jornais, publicações na mídia impressa e na mídia digital e observações de campo nos arredores da escola e na cidade.

A metodologia adotada pode ser classificada como sendo de ordem qualitativa e representa as fases empregadas durante a investigação. Trata-se de um "ato dinâmico de questionamento, indagação e aprofundamento em busca de uma resposta significativa para o problema, buscando desvelar a verdade que o fato encerra". Portanto, ela visa "atingir o melhor índice de fidelidade do conhecimento que esta sendo investigado" (BARROS; LEHFELD, 2007).

Segundo Barros e Lehfeld (2007, p. 106) o questionário é o instrumento normalmente mais utilizado para o levantamento de informações. Ele pode ser "fechado" ou "aberto", porém, deve haver a preocupação com a clareza das questões e, ele não deve ser exaustivo, a fim de não destimular o informante a responder. No nosso caso, optamos por questões abertas, que permitem uma liberdade nas respostas dos sujeitos da pesquisa. Como todo instrumento de coleta de dados, os questionários possuem vantagens e desvantagens. 
O desenvolvimento do trabalho ocorreu durante aproximadamente (3) meses, mas por questão de clareza na apresentação da sequência metodológica, dividiremos o trabalho em 3 etapas, que serão apresentadas a seguir:

1a. etapa: Aplicação, em sala de aula, de um questionário aberto (Anexo 1) a fim de compreender o conceito, baseado no conhecimento prévio de senso comum, que os alunos possuem sobre os temas "polímeros", "lixo" e "reciclagem" e, também, a importância que eles atribuem à reciclagem do lixo. É pertinente ressaltar que o questionário aberto faz parte de uma metodologia investigativa, na qual é baseada por uma sequência de questões escritas que foram dirigidas a um conjunto de alunos, envolvendo suas opiniões, representações e informações sobre eles próprios e o meio. O questionário foi realizado visando não causar nenhum tipo de constrangimento, deixando os alunos à vontade para que expusessem as suas ideias, de forma espontânea e pessoal.

2ª . etapa: Após a análise dos resultados e das observações realizadas, foi apresentado um seminário, ministrado pela pesquisadora e autora deste artigo, destacando a importância dos polímeros na sociedade, seguido dos problemas e soluções possíveis para os resíduos poliméricos. A finalidade do seminário foi disseminar o conhecimento sobre a temática proposta, a fim de subsidiar os alunos com conteúdos conceituais sobre os plásticos e polímeros e com lições de cidadania.

$3^{a}$. etapa: Desenvolver juntamente com os alunos, integrantes da nossa amostra, propostas de conscientização para a comunidade, que pudessem ser efetivamente realizadas. Porém, embora os alunos tenham apontado ações que extrapolassem os "muros" escolares visando a reciclagem e a preservação o meio ambiente, elas não foram efetivadas durante esta pesquisa.

Portanto, basicamente nosso instrumento de análise se pautou no questionário prévio sobre as concepções que os alunos expuseram em suas respostas. Como se trata de um questionário aberto, a pesquisadora elaborou algumas categorias a fim de simplificar as informações apresentadas ao leitor. Os Gráficos 1 e 2 sintetizam nossos resultados apresentando as porcentagens referentes a cada categoria.

\section{Apresentação e Análise dos Resultados}

Os resultados foram obtidos por meio do Questionário (etapa 1) apresentado no Anexo 1. Este instrumento foi utilizado visando um levantamento prévio das concepções dos alunos e, é composto por 5 (cinco) questões abertas que foram respondidas pelos participantes da pesquisa. Além dos Gráficos 1 e 2, são apresentados trechos relevantes da "fala" dos alunos a fim de ilustrar o trabalho realizado. Esses trechos representam apenas uma 
síntese das principais categorias, dado a impossibilidade de apresentar os resultados completos no escopo deste artigo.

As Questões 1 e 2 investiga o que os alunos entendem por "polímeros" e "plásticos", respectivamente. De acordo com os resultados apenas "7,7\%" da amostra investigada conseguiu conceituar os polímeros; 0 restante dos respondentes não conseguiu sequer associar o uso desses materiais no seu dia a dia. As respostas mais recorrentes para a Questão 1 foram que os alunos "não entendem nada" ou "não conhecem nada sobre polímeros". Quanto aos plásticos, um total de " $40,6 \%$ " definiram os plásticos corretamente, o restante dos alunos não soube definir o conceito e/ou citar exemplos do uso desses materiais no cotidiano. Nestes casos, devido a simplicidade dos dados obtidos com as porcentagens, optamos por apresentar os valores diretamente, ao invés de apresentar tabelas ou gráficos.

Quando perguntado da importância dos plásticos na sociedade, por meio da Questão 3, a maioria dos alunos "40\%" citou o uso de sacolas plásticas do supermercado, conforme dados do Gráfico 1. Isso é preocupante, pois, evidencia que os alunos não possuem o conhecimento adequado para compreender que as sacolas plásticas podem ser substituídas por alternativas mais sustentáveis e que a importância e as aplicações dos plásticos vão muito além das sacolinhas. Dentre os alunos, apenas "37\%" atribuíram aos plásticos como sendo muito importante para a sociedade e, citaram exemplos de indústrias de alimentos, automóveis e tecnologia.

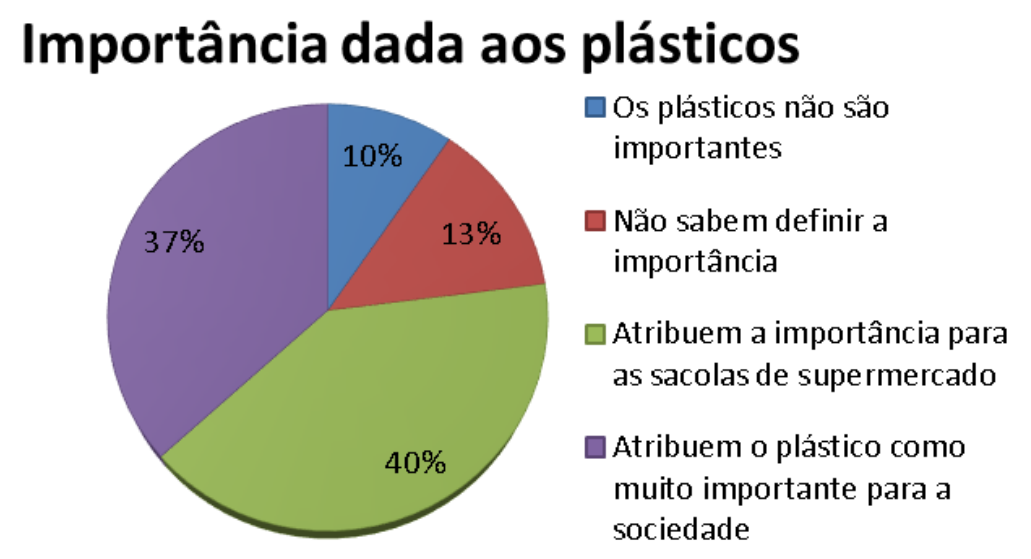

Gráfico 1: Porcentagem da importância dada aos plásticos pelos alunos.

Devemos ainda considerar que, "13\%" dos alunos responderam que o plástico não é importante para a sociedade, pois, segundo eles, "esses materiais são derivados do petróleo e poluem o meio ambiente". Nesse ponto, vale a pena frisar o quanto é importante uma educação ambiental eficiente, 
pois somente assim, esses estudantes poderão adquirir a consciência de que esses materiais só irão prejudicar o meio ambiente se forem descartados de forma errada, e que existem formas de se trabalhar com o lixo, e, além disso, eles mesmos têm papel importante no desenvolvimento sustentável.

Conforme os dados do Gráfico 1, verifica-se que "10\%" não consegue reconhecer importância de um material que usa diariamente. Isso demonstra que os alunos não estão inseridos nas questões que envolvem a sociedade, ou seja, eles não conseguem discutir a importância, por exemplo, dos polímeros, para o desenvolvimento econômico e tecnológico do país em que vivem, e essa problemática se estende para qualquer questão social.

É necessário mostrar a importância do estudo e conhecimento, (mesmo que baseado no senso comum), dos polímeros aos alunos e, até mesmo, por que esses materiais estão cada vez mais presentes em nosso cotidiano e se tornaram essenciais para a vida moderna.

Quanto importância da reciclagem, abordada na Questão 4, os resultados também não foram animadores. As respostas mais significativas para esta questão foram: "é importante para preservação do meio ambiente, mas nunca tive aula sobre o assunto". De acordo com o Gráfico 2, "62\%" dos alunos alegaram que nunca tiveram aulas sobre conscientização ambiental ao longo de sua jornada escolar. Eles sabem da importância da reciclagem, dos impactos ambientais que o lixo pode causar no meio ambiente, mas não possuem uma postura de preservação, e isso se deve a falta de uma educação ambiental consistente. Um total de "21\%" dos sujeitos investigados não lembra se já teve alguma aula sobre o assunto e, apenas "17\%" admitem que algum dia, durante sua formação escolar, teve contato com o tema "Educação Ambiental".

\section{Aula sobre Educação Ambiental}

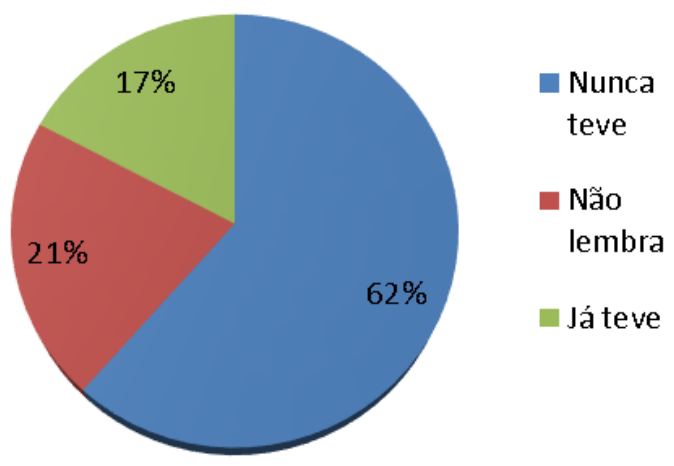

Gráfico 2: Resultados da porcentagem de alunos que já tiveram aula de educação ambiental nas escolas. 
Fica evidente que a maior parte dos profissionais da educação ainda está muito distante da realidade emergencial relacionada aos objetivos da educação ambiental e, dessa forma, se faz necessário o apoio do governo na preparação dos professores para trabalhar com esse tema tão complexo dentro da sala de aula. É válido ressaltar que a reciclagem não é um tema isolado, mas sim, que permeia todo o modo de vida de uma população, já que os problemas ambientais não só preocupam, mas atingem a todos, sem distinção. Desse modo, a educação e a consciência ambiental são as melhores saídas para conciliar o progresso, a agilidade e o consumo sustentável dos materiais plásticos, que também são fontes de energia, geração de emprego e renda.

Com base nas análises dos questionários, foi ministrado um seminário (etapa 2) abordando a importância dos materiais poliméricos na sociedade, sua utilização e quais os métodos possíveis de reciclagem. A abordagem foi interessante para os alunos, pois foi feita uma ligação concreta com a realidade social, e isso, estimulou e despertou neles uma preocupação com o meio ambiente. Através dessa abordagem, os alunos puderam tirar suas dúvidas quanto o manuseio correto de diversos materiais, quais os possíveis meios de reciclar, foi apresentado a eles diversas aplicações dos polímeros, além disso, foi discutido como a Ciência e Tecnologia dos Polímeros se desenvolveu ao longo dos anos na sociedade e, de que modo isso influenciou nos padrões de vida das pessoas em todo o mundo e, por fim, foi feito um debate sobre de que maneira podemos contribuir para a sustentabilidade. Portanto, o seminário além de esclarecer muitas dúvidas existentes, também se revelou bastante motivador.

Através do debate, e da Questão 5, os alunos apresentaram propostas de conscientização ambiental que pudessem ser estendidas para toda a comunidade (etapa 3). Dentre as propostas, destacou-se a ideia de um mutirão realizado pelos próprios alunos. Esse mutirão teria como objetivo sair pelas ruas da cidade explicando o que são polímeros e sua importância para 0 desenvolvimento da sociedade, e, além disso, conscientizar a população sobre o impacto ambiental que esses materiais podem causar se forem descartados de forma incorreta. Os alunos ainda apresentaram a ideia de criar folders ilustrativos sobre a separação correta dos materiais poliméricos e distribuir para a comunidade, facilitando assim a coleta seletiva. Também houve propostas de palestras sobre reciclagem, convidando pessoas que trabalham com a reciclagem do lixo, além disso, os alunos propuseram gincanas educativas comunitárias, na qual, toda a comunidade pudesse participar e se conscientizar a respeito. 


\section{Considerações finais}

Este trabalho abordou como objeto de pesquisa dois produtos com inúmeras aplicações em nosso cotidiano: os polímeros e os plásticos. $O$ objetivo da investigação foi desenvolver um processo formativo com os alunos, apresentando a eles as características destes materiais e revelando suas utilidades. Além disso, objetivamos conscientizar os alunos, por meio da educação ambiental, para uma mudança de atitude em relação ao consumo de produtos descartáveis, instruindo-os como coletar e separar os plásticos para serem encaminhados a uma cooperativa de reciclagem.

Os resultados do questionário prévio permitiram observar que os alunos participantes apresentam conhecimentos bastante precários com relação a polímeros, plásticos, sua importância na sociedade, bem como, eles demonstraram que não possuem hábito de reciclagem e reutilização de resíduos. O questionário deixou evidente que os alunos não conhecem muito bem a sociedade em que estão inseridos, e assim, faz-se necessário que as escolas abordem temas como desenvolvimento social, econômico, ambiental, dentre outros, para que eles conheçam melhor como funciona o mundo onde vivem.

Lembrando que, não se forma cidadãos conscientes apenas com conteúdos teóricos; é necessário levar os problemas sociais e reais para dentro da sala de aula, abordar, discutir e contextualizar os mais variados temas que afligem e permeiam toda a sociedade, pois assim, eles passam a compreender melhor como funciona o mundo onde vivem e de que forma suas ideias e atitudes podem transformar seu futuro.

No presente trabalho, usamos o tema polímeros, levando a uma dinâmica de aprendizagem na qual o aluno pudesse refletir sobre sua importância, nos mais variados setores, sua abrangência, economia, dentre outros, e somente assim, ser capaz de assumir uma postura crítica quanto a sustentabilidade.

Podemos inferir por meio dos resultados que é possível levar para dentro da sala de aula questões como a importância dos polímeros na sociedade e contextualizar este tema com a educação ambiental. Embora os resultados tenham sido significativos do ponto de vista de subsidiar o presente trabalho, percebe-se que os mesmos não são suficientes. Afinal, não serão ações isoladas que resolverão o problema da educação ambiental nas escolas públicas.

A educação ambiental deve ser um programa permanente da escola, para que seja suficiente modificar a atitude da comunidade escolar e local. Neste sentido, as propostas feitas pelos alunos deveriam ser implementadas visando efetivar ações concretas. Almejamos que isso seja feito em breve. Para isso, achamos que a elaboração de Projetos visando integrar alunos das escolas públicas nesta empreitada, seria extremamente interessante. 


\section{Referências}

ALMEIDA, E. M. P.; MONTANHA, S. M.; SANTANA, P. M. C.; SOARES, L. C. B. Educação Ambiental na escola: um estudo da relação entre a alimentação e a produção de resíduos. Revista Brasileira de Educação Ambiental, v. 7, n. 2, p. 131-149, 2013.

BARROS, A.J.S.; LEHFELD, N.A.S. Fundamentos de Metodologia Científica. 3ª . ed.; São Paulo: Pearson Prentice Hall; 2007.

BOTELHO, G.; Química, Degradação e Reciclagem de Polímeros, Apontamentos da Unidade curricular, Química Tecnologia e Novos materiais, Departamento Química; Universidade do Minho, 2011.

BRASIL, MINISTÉRIO DA EDUCAÇÃO, Vamos cuidar do Brasil: conceitos e práticas da educação ambiental na escola. / Ministério da Educação. Coordenação Geral de Educação Ambiental: Ministério do Meio Ambiente, Departamento de Educação Ambiental, UNESCO: 2007.

BRASIL, MINISTÉRIO DA EDUCAÇÃO E CULTURA, Diretrizes Curriculares Nacionais Gerais da Educação Básica / Ministério da Educação. Secretaria de Educação Básica. Diretoria de Currículos e Educação Integral, Brasília: MEC, SEB, DICEI, 2013.

CANEVAROLO, S.; Ciência dos Polímeros: um texto básico para tecnólogos e engenheiros. São Paulo, Artliber Editora, 2002.

CANGEMI, J.M.; SANTOS, A.M.; CLARO NETO, S. Biodegradação: Uma Alternativa para Minimizar os Impactos Decorrentes dos Resíduos Sólidos. Química Nova na Escola, n. 22, p 17-21, nov/2005.

DE PAOLI, M.A., Degradação e estabilização de polímeros, $2^{\underline{a}}$ versão on-line (revisada), 2008.

FRANCHETTI S.M.M.; CANGEMI, J.M.A importância da Propriedades Física dos Polímeros na Reciclagem. Química Nova na Escola, n. 18, p 42-45, nov/2003.

GIESSE, R. O futuro dos plásticos: biodegradáveis e fotodegradáveis. Polímeros: Ciência e Tecnologia, v. 13, n. 4, p. E4-E6, 2003.

MANO, E. B; MENDES, L.C., Introdução a Polímeros, Edgard Blücher, $2^{\mathrm{a}}$. edição, 1999. 
MARCONDES, M.E.R.; CARMO, M.P,; SUART, R.C.; SILVA, E.L.; SOUZA, F. L.; SANTOS JR., J.B.; AKAHOSHI, L.H., Materiais instrucionais numa perspectiva CTSA: uma análise de unidades didáticas produzidas por professores de química em formação continuada, Investigações em Ensino de Ciências,vol. 14(2), 281-298, 2009.

MATTOS, N.C.M.; PERES, P.E.C. Coletar e reconhecer o plástico: uma atitude em educação ambiental. Revista Eletrônica em Gestão, Educação e Tecnologia Ambiental, v. 1, n. 1, p. 01-12, 2010.

MAZZARINO, J.M.; MUNHOZ, A.V.; KEIL, J.L. Currículo e transversalidade em Educação Ambiental. Revista Brasileira de Educação Ambiental, v. 8, n. 2, p. 51-56, 2012.

MESQUITA, G.S.; OLIVEIRA, D.X.; SILVA FILHO, C.I.; ANDRADE, W.A.S.; ALMEIDA, D.C.; LIMA, J.P.M. Plásticos, Coleta Seletiva e Reciclagem: Diferentes Estratégias para o Ensino de Polímeros. In: Anais XV Encontro Nacional de Ensino de Química (XV ENEQ), Brasília, 2010.

OLIVEIRA, A.M. O ensino do tema polímeros na perspectiva da educação dialógica com enfoque CTS: reflexões e ações. Dissertação (Mestrado em Ensino de Ciências), Universidade Federal do Mato Grosso do Sul, UFMS, Campo Grande, 2010. 188p.

OZÓRIO, M. Polímeros na sociedade: utilização e reciclagem - uma abordagem para o ensino. Trabalho de Conclusão de Curso (Licenciatura em Física). Faculdade de Ciências e Tecnologia. Universidade Estadual Paulista: Presidente Prudente, 2013.

REIS, T. M.; MELO, M. R.; Avaliação do Comprometimento socioambiental na aplicação dos projetos elaborados pelos licenciandos de Química licenciatura da UFS, Scientia Plena, vol. 9, ํㅡ. 7, 2013

SANTOS, P. T. A.; DIAS, J.; LIMA, V. E.; OLIVEIRA, M. J.; NETO, L. J. A.; CELESTINO, V. Q., Lixo e reciclagem como tema motivador no ensino de química, Ecl. Quím., São Paulo, vol. 36, 2011. 